\title{
Association between amniotic fluid index at term and ultrasound estimation of fetal weight and actual birth weight: an observational cross-sectional study
}

\author{
Laxmi Umeshappa, Ashwini Harish Pai, Arpitha VJ, Aman James, Abijith KV, Mahesha \\ Corresponding author: Dr. Ashwini Harish Pai, Professor, Department of Obstetrics and \\ Gynecology, Subbaiah Institute of Medical sciences, Purle, Shimoga, Karnataka, India; \\ Email : ashwiniharishpai@gmail.com
}

Distributed under Attribution-Non Commercial - Share Alike 4.0 International (CC BY-NC-SA 4.0)

\begin{abstract}
Objectives: To study the influence of amniotic fluid volume at term gestation with accuracy in fetal weight estimation by ultrasound. Methods: Retrospective observational cross-sectional study was done in 358 term deliveries over a period of two years from January 2019 to December 2020 in a medical college hospital. All singleton term pregnancies that had an ultrasound estimation of fetal weight and amniotic fluid within a week of delivery were included, irrespective of parity, age and mode of delivery. Error in estimation of fetal weight was calculated with reference to actual birth weight and comparisons were made to note the degree of accuracy across varying amniotic fluid volume by applying ANOVA and Tukeys test. Results: Mean error in fetal weight estimation was not significant with respect to parity index, gestational age or fetal gender. There was a significant $(p=0.001)$ increasing mean birth weight with increasing amniotic fluid volume and the error in estimation of fetal weight was significant across all AFI groups $(p=0.014)$. Mean error in oligoamnios group was significantly lesser than normal liquor $(p=0.041)$ and high normal $(p=0.032)$ at a $5 \%$ level of significance. Hence, the estimation of fetal weight in the oligoamnios group was more accurate. Conclusion: Amniotic fluid volume and ultrasound fetal weight estimation are mostly independent variables though they are factors of gestational age. Consistent errors are seen across varying AFI. The noticeable accuracy in the low liquor group is reassuring as oligoamnios is frequently associated with low birth weight.
\end{abstract}

Keywords: Amniotic fluid index, ultrasound, estimated fetal weight.

Amniotic fluid (AF) and fetal weight are important determinants of labour management and perinatal outcome ${ }^{1}$. Amniotic fluid cushions the growing fetus and nourishes it throughout pregnancy. Physiological variations in level of amniotic fluid are noted with progressing gestation. Amniotic fluid is an indirect indicator of placental perfusion. Also, in later pregnancy, it reflects fetal wellbeing. It therefore is a core component of biophysical profile in antenatal fetal monitoring.

Fetal weight reflects in-utero environment and assists in assessing the progress of pregnancy. Planning of how, when and where of labor and delivery does depend on estimated fetal weight and period of gestation. Fetal weight may be a factor of gestational age but in-utero influences like medical disorders or infections may alter growth of the fetus. Lower and higher fetal weights both may warrant neonatal admissions for respiratory and electrolyte imbalances.

Ultrasound remains an essential non-invasive tool in assessing AF volume ${ }^{2}$ and estimating fetal weight. Amniotic fluid can be assessed by the popular four quadrant (amniotic fluid index) technique ${ }^{3}$, single vertical pocket and subjective estimation by an experienced sonologist ${ }^{4}$. Oligohydramnios is found to be associated with higher perinatal morbidity and may be an indication for prompt delivery ${ }^{5}$.

Received: $2^{\text {nd }}$ March 2021, Peer review completed: $4^{\text {th }}$ April 2021, Accepted: $13^{\text {th }}$ April 2021.

Umeshappa L, Pai AH, Arpitha VJ, James A, Abijith KV, Mahesha. Association between amniotic fluid index at term and ultrasound estimation of fetal weight and actual birth weight: an observational cross-sectional study. The New Indian Journal of OBGYN. 2022; 8(2): 299 - 303. 
Fetal weight estimation is done by measuring dynamic fetal parameters like biparietal diameter, abdominal and head circumference and femur length. Accuracy in fetal weight estimation depends on sonologist's expertise, ultrasound machine, fetal position, placental location, fetal sex, interval between estimation and delivery ${ }^{6}$.

Fetal weight and amniotic fluid both being factors of gestational age, vary independently and in conjunction with one another depending on individual pregnancy conditions. It would be interesting to note whether amniotic fluid index would influence fetal weight estimation by ultrasound. Contradictory observations were noted across various studies $^{7-12}$. Though oligoamnios may be associated with growth restriction and low birth weight, would it hamper ultrasound fetal weight estimation will be interesting to note. The volume of liquor amnii may alter fetal position which may alter fetal measurements. Usually, the accuracy of fetal weight estimation at term has been inconsistent depending on comparative models that are selected for that population $^{11}$. Controversy exists on the effects of varying amniotic fluid levels on the accuracy of fetal weight estimation. We attempt to note the possible influence of amniotic fluid levels on accuracy of estimating fetal weight.

\section{Materials and methods}

This retrospective observational cross sectional study to determine the association of amniotic fluid index (AFI) at term gestation ( 37 weeks to 42 weeks) with the accuracy of ultrasound estimation of fetal weight, was conducted in the department of obstetrics and gynecology at the teaching hospital of Subbaiah institute of Medical sciences, Shivamogga, Karnataka, India for a period of 2 years from January 2019 to December 2020. Study protocol was determined and clearance was obtained from the institutional ethical committee.

All term deliveries in the prescribed period that had an ultrasound report within a week of delivery, irrespective of their age, mode of delivery and parity index were included. Preterm deliveries and women who did not have an ultrasound report within a week of delivery were excluded.
Ultrasound estimated weight of each baby was noted. This was then compared with actual birth weight to note the accuracy of estimation. Comparisons were made as to whether accuracy varied in the different groups of AFI. ANOVA was used for overall comparison of mean birth weight (BW), estimated fetal weight (EFW) and error in estimation. Tukeys test was done for pair wise comparison between different AFI groups. $\mathrm{P}$ value less than 0.05 was considered statistically significant.

\section{Results and observations}

A total of 358 term deliveries were included, of which $65.4 \%$ were multigravidas and the remaining primigravidas. The mean age of our women was 25.6 years with range of 19 to 37 years. A high rate of caesarean section $(82.7 \%)$ was noted and most of them (53.4\%) were multigravidas with previous LSCS.

In the multigravidas, the mean birth weight (BW) was $2.84 \mathrm{~kg} \pm 0.37$ and the mean estimated fetal weight (EFW) was $2.69 \mathrm{~kg} \pm 0.42$. Similarly, in the primigravidas, the mean $\mathrm{BW}$ was $2.87 \mathrm{~kg} \pm 0.42$ and mean $\mathrm{EFW}$ was $2.73 \mathrm{~kg} \pm 0.4$. Comparing the mean error in estimation with respect to parity was not significant.

Majority of the women delivered prior to their expected date of delivery $(55.2 \%$ delivered between 37 to 38 completed weeks, $44.5 \%$ between 39 to 40 completed weeks and only $0.3 \%$ after 40 weeks). A significant increase in the mean BW was noted as the period of gestation advanced. But, the error in fetal weight estimation was not seen to be significant across the varying period of gestation.

The girl baby to boy baby ratio was seen to be $45.3 \%$ to $54.7 \%$. Boys (mean BW 2.90kg \pm 0.38 and mean $\mathrm{EFW}$ $2.75 \mathrm{~kg} \pm 0.37$ ) were seen to be heavier than girl babies (mean BW $2.79 \mathrm{~kg} \pm 0.39$ and mean EFW $2.6 \mathrm{~kg} \pm 0.37$ ). There was no significant error in fetal weight estimation across gender of the baby.

Cases were stratified into four groups depending on AFI. Three-fourth (76.26\%) belonged to group C with a AFI of 9 to $18 \mathrm{~cm}$, whereas, $3.35 \%$ were in group A with oligoamnios, $10.6 \%$ women had low normal liquor (AFI of 5 to $8 \mathrm{~cm}$, that

Table 1: Showing estimated fetal weight, birth weight and error across AFI groups.

\begin{tabular}{|c|c|c|c|c|c|c|}
\hline \multirow{2}{*}{$\begin{array}{l}\text { AFI groups } \\
\text { (N) }\end{array}$} & \multicolumn{2}{|c|}{ Birth weight in $\mathrm{Kg}$} & \multicolumn{2}{|c|}{ Estimated fetal weight in $\mathrm{Kg}$} & \multicolumn{2}{|c|}{ Error in estimation } \\
\hline & Mean & Standard deviation & Mean & Standard deviation & Mean & Standard deviation \\
\hline Group A (12) & 2.60 & 0.29 & 2.62 & 0.26 & 0.10 & 0.06 \\
\hline Group B (38) & 2.62 & 0.37 & 2.60 & 0.32 & 0.22 & 0.24 \\
\hline Group C (273) & 2.88 & 0.38 & 2.71 & 0.38 & 0.29 & 0.23 \\
\hline Group D (35) & 2.98 & 0.39 & 2.81 & 0.41 & 0.32 & 0.26 \\
\hline $\mathrm{P}$ value & 0.001 & & 0.118 & & 0.014 & \\
\hline
\end{tabular}

Cases were divided into four groups depending on their

is group B). The remaining $9.7 \%$ women belonged to group AFI (group A: AFI less than $5 \mathrm{~cm}$, group B: AFI 5 to $8 \mathrm{~cm}$, $\mathrm{D}$ with AFI in the higher range. It was noted that there was a group C: AFI 9 to $18 \mathrm{~cm}$, group D: AFI 19 to $25 \mathrm{~cm}$ ).

significant $(p=0.001)$ increasing mean birth weight with 
increasing amniotic fluid volume. Also, the mean estimated fetal weight was showing an increasing trend with increasing AFI. It was found that the error in estimation of fetal weight was significant across all AFI groups $(\mathrm{p}=0.014)$ (table 1).

Interestingly, the error between actual birth weight and ultrasound estimated fetal weight was lesser in oligoamnios group. Mean error in Group A was significantly lesser than group $\mathrm{C}(\mathrm{p}=0.041)$ and group $\mathrm{D}(\mathrm{p}=0.032)$ at a $5 \%$ level of significance. Hence, the estimation of fetal weight in the

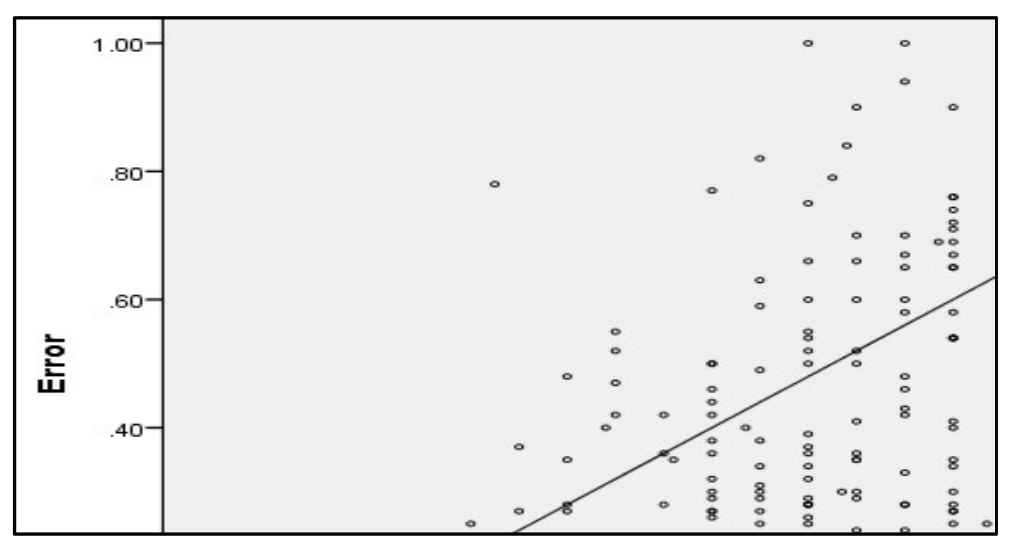

Figure 1: Linear regression graph showing error in fetal weight estimation plotted against AFI

oligoamnios group was more accurate. And, as the liquor volume increases, so did the error in fetal weight estimation (figure 1).

\section{Discussion}

The measurement of amniotic fluid index and estimation of fetal weight by ultrasound at term gestation was found to be independent of each other, though commonly there seems to be an association between their simultaneous occurrences.

Ultrasound estimation of fetal weight depends on fetal biometry. Measurement of fetal parameters may be dependent on maternal abdominal wall obesity, experience of the sonologist, ultrasound machine and the software used to estimate fetal weight ${ }^{5}$. Also, dynamic variables like fetal position at examination, gestational age, placental location, amniotic fluid volume may affect fetal biometry. Tas $\mathrm{EE}^{13}$ concluded that primiparity and cephalic presentation of the fetus were independent risk factors for errors in sonological fetal weight estimation. Contrarily, comparing the mean error in fetal weight estimation with respect to parity was not significant in our study population.

Calculation of error of estimation depends on ultrasound examination to delivery interval. The best accuracy of sonographic fetal weight estimation with the commonly used equations was achieved within a scan to delivery interval of one week ${ }^{14}$. All the women in our study had undergone an ultrasound estimation of fetal weight within a week prior to delivery.

Through a prospective study in central India, Wadnere et $\mathrm{al}^{9}$ concluded that there was no linear correlation between amniotic fluid index and estimated fetal weight though they are factors of gestational age. They suggested that fetal size need not be taken into consideration when alterations in amniotic fluid are noted. Similar inference was drawn by Adeyakun AA et $\mathrm{al}^{15}$ in a Nigerian population. Similar results were seen in our study that though more liquor was associated with bigger babies, there was no linear correlation as such.

Ashwal E et $\mathrm{al}^{7}$ evaluated accuracy of sonographic fetal weight estimation with respect to AF variation and found that AFI had limited impact on error in fetal weight estimation within a week of delivery in oligoamnios, normal liquor and polyhydramnios. Janas $\mathrm{P}$ et $\mathrm{al}^{8}$ studied women who had estimation to delivery interval within 48 hours and found that in term pregnancies with isolated oligohydramnios, lower liquor had limited impact on fetal weight estimation and there was a tendency to overestimate fetal weight. Karahanoglu E et a ${ }^{12}$ studied term pregnancies with oligoamnios and polyhydramnios and compared the error in fetal weight estimation. They concluded that there were no significant differences in the accuracy of fetal weight estimation in both oligo and polyhydramnios. However, there was an apparent overestimation in both the groups.

In our cohort, the error in estimated fetal weight was consistent $(\mathrm{p}=0.014)$ across all groups of AFI. However, in women with oligoamnios, the error in fetal weight estimation was significantly lesser than the groups with normal and high AFI. In clinical practice, oligoamnios and a probable low birth weight has been a factor to plan impending delivery and neonatal care. Ultrasound based fetal weight estimation is taken as a substitute for actual birth weight. Inaccurate fetal weight estimation can lead to unnecessary or delayed interventions, thus increasing the maternal and fetal risks. The knowledge of a possible more accurate fetal weight estimation in oligoamniosis most assuring as we may be able to foresee any untoward perinatal outcome. This better accuracy may be attributed to a more fixed position of thefetus where measurement of fetal parameters becomes easier. 
The New Indian Journal of OBGYN. 2021 (January-June);8(2)

Hiwale $\mathrm{S}$ et $\mathrm{al}^{11}$ reported that out of all factors possibly affecting fetal weight estimation, only fetal gender was found to have a significant positive correlation, with the male fetuses having statistically significant less error. They stressed the need for customised population based formulas for fetal weight estimation. Agwu EJ et $\mathrm{al}^{10}$ established an AFI normogram in the third trimester for the local Nigerian population and noted a positive significant correlation between AFI and estimated fetal weight at all gestational age. When analysed with respect to fetal gender, no significant correlation was seen in male fetuses as opposed to female fetuses that showed a positive correlation. Established fetal weight should be taken into account when interpreting AFI for female fetuses but this need not be applied for male fetuses. We noticed that male babies were heavier than girls. This was found to be consistent at all gestational age, parity and also the AFI groups. There was no significant error in fetal weight estimation across gender of the baby.

The studied population was a single centre study of all term pregnancies that included both low risk and high risk pregnancies. Low sample size in the oligoamnios group may be a limitation and warrant further observation.

\section{Conclusion}

Amniotic fluid volume in itself may not influence ultrasound fetal weight estimation as consistent errors are seen across varying AFI. However, the noticeable accuracy in the low liquor group is reassuring as oligoamnios is frequently associated with low birth weight that may have a turbulent neonatal period.

\section{Conflict of interest: None. Disclaimer: Nil.}

\section{References}

1. Krispin E, Dreyfuss E, Fischer O, Wiznitzer A, Hadar E, Bardin R. Significant deviations in sonographic fetal weight estimation: causes and implications. Arch Gynecol Obstet. 2020; 302(6):1339-44.

2. Moore TR. The role of amniotic fluid assessment in evaluating fetal well-being. Clin Perinatol. 2011; 38(1): 33-46.

3. Phelan JP, Ahn MO, Smith CV, Rutherford SE, Anderson E. Amniotic fluid index measurements during pregnancy. Journal of Reproductive Medicine for the Obstetrician and Gynecologist. 2010; 32(8): 601- 4.

4. Fuchs F, Aouinti S, Souaied M, Keller V, Picot MC, Fries N, et al. Association between amniotic fluid evaluation and fetal biometry: a prospective French "Flash" study. Scientific Reports. 2018; 8: 7093.

5. Iqbal S, Noreen A. Low amniotic fluid index as a predictor of perinatal outcome in low risk pregnancies at term. Pakistan Journal of Medical and Health sciences. 2010; 4(3): 270-71.

6. Huber C, Zdanowicz JA, Mueller M, Surbek D. Factors influencing the accuracy of fetal weigth estimation with a focus on preterm birth at the limit of viability: a systematic literature review. Fetal DiagnTher. 2014; 36(1): $1 \mathrm{e} 8$.

7. Ashwal E, Hiersch L, Melamed N, Bardin R, Wiznitzer A, Yogev Y. Does the level of amniotic fluid have an effect on the accuracy of sonographic estimated fetal weight at term? J Matern Fetal Neonatal Med. 2015; 28(6): 638-42.

8. Janas $\mathrm{P}$, Radoń-Pokracka $\mathrm{M}$, Nowak $\mathrm{M}$, Staroń A, Wilczyńska G, Brzozowska $\mathrm{M}$, et al. Effect of oligohydramnios on the accuracy of sonographic foetal weight estimation in at term pregnancies. Taiwan J Obstet Gynecol. 2019 Mar; 58(2): 278-81.

9. Wadnere N, Kosta SR, Kumar R. Association between fetal weight and amniotic fluid index in women of Central India. Adv Biomed Res. 2014; 3:243.

10. Agwu EJ, Ugwu AC, Shem SL, Abba M. Relationship of amniotic fluid index (AFI) in third trimester with fetal weight and gender in a southeast Nigerian population. Acta Radiol Open. 2016; 5(8): 1-5.

11. Hiwale S, Firtion C. Analysis of factors influencing accuracy of ultrasound-based fetal weight estimation. Indian J Radiol Imaging. 2020; 30(2): 156-62.

12. Karahanoglu E, Altinboga O, Akpinar F, GultekinI B, Ozdemirci S, Akyol A, et al. The Effect of the Amniotic Fluid Index on the Accuracy of UltrasonographicEstimated Fetal Weight. Ultrasound Q. 2017; 33(2): 148-52.

13. Tas EE, Kir EAG, Yilmaz G, Yavuz AF. Accuracy of sonographic fetal weight estimation in full-term singleton pregnant women. Pak J Med Sci. 2019; 35(1): 34-8.

14. Faschingbauer F, Raabe E, Heimrich J, Faschingbauer C, Schmid M, Mayr A, et al. Accuracy of sonographic fetal weight estimation: influence of the scan-to-delivery interval in combination with the applied weight estimation formula. Arch Gynecol Obstet. 2016; 294(3): 487-93.

15. Adeyekun AA, Awosanya GG. Relationship between Amniotic Fluid Index and Ultrasound Estimated Fetal 
The New Indian Journal of OBGYN. 2021 (January-June);8(2)

Weight in Healthy Pregnant African Women. Journal of Clinical Imaging Science. 2013; 3(1): 1- 4.

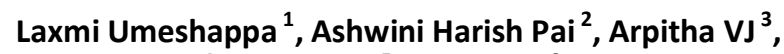
Aman James ${ }^{4}$, Abijith $\mathrm{KV}^{5}$, Mahesha ${ }^{6}$

${ }^{1}$ Assistant Professor, Department of Obstetrics and Gynecology, Subbaiah Institute of Medical Sciences, Purle, Shimoga, Karnataka, India; ${ }^{2}$ Professor, Department of Obstetrics and Gynecology, Subbaiah Institute of Medical sciences, Purle, Shimoga,

Karnataka, India; ${ }^{3}$ Assistant Professor, Department of
Obstetrics and Gynecology, Subbaiah Institute of Medical sciences, Purle, Shimoga, Karnataka, India; ${ }^{4}$ Junior Resident, Department of Obstetrics and Gynecology, Subbaiah Institute of Medical Sciences, Purle, Shimoga, Karnataka, India; ${ }^{5}$ Junior Resident, Department of Obstetrics and Gynecology, Subbaiah Institute of Medical Sciences, Purle, Shimoga, Karnataka, India; ${ }^{6}$ Biostatistician, Department of community medicine, Subbaiah Instituteof Medical Sciences, Purle, shimoga, Karnataka, India. 